\title{
Enhancing the Role of Analytical Procedures in Financial Intelligence Service as an Integral Part of the Regulatory and Financial Technologies Development
}

\section{Stepanko A. D. and Surnina K. S.}

Institute of Economics and Management (structural unit) FGAOU VO "Crimean Federal University behalf of V.I. Vernadsky", Russia, 295015, the Republic of Crimea, Simferopol

\section{Abstract}

The article describes the main trends in the development of regulatory and financial technologies and touches upon the problems and prospects of development for the world and Russian economy. It also justifies the necessity of conducting qualitative analytical procedures in the conditions of a changing market structure.

Corresponding Author:

Surnina K. S.

surnina2o@mail.ru

Received: 11 December 2017

Accepted: 20 January 2018

Published: 13 February 2018

Publishing services provided by Knowledge $\mathrm{E}$

(c) Stepanko A. D. and Surnina K.

S.. This article is distributed

under the terms of the

Commons Attribution License,

which permits unrestricted use and redistribution provided that the original author and source are credited.

Selection and Peer-review under the responsibility of the FinTech and RegTech: Possibilities, Threats and Risks of Financial Technologies Conference Committee.

\section{Introduction}

Financial technologies (hereinafter referred to as Fintech) and regulatory technologies (hereinafter referred to as Regtech) are the main mechanisms for increasing the efficiency of financial transactions using the latest achievements of scientific and technical progress. These mechanisms make it possible to simplify the process from the beginning of the operation to its reflection in the financial statements. For small or newly established companies, such platforms are preferable because they don't require perfect knowledge of the legislation and operating conditions according to maximum automation. Despite the presence of the branched out structure itself they guarantee the reduction of the human factor and time costs influence for large corporations.

\section{The main material}

The development of financial technologies began at the end of the zoth century as an alternative variant of the banking payment system. Financial technologies are the system that uses modern technologies and innovations to create competition for traditional financial organizations, such as banks and other intermediaries of the financial market. Fintech's activities are focused on optimizing the process of providing financial 
services, both in terms of reducing the time frame, and increasing the total number of transactions due to ubiquitous access to their electronic funds. Nowadays Fintech is a huge industry with a high level of capitalization. The popularity of start-ups in this industry is determined by easy use of applications through any device that has access to the Internet, an alternative variant of money circulation bypassing the traditional banking system and the possibility of simultaneous services of several counterparties.

Concerning the basic directions of financial innovations development, we consider it necessary to include:

- Money transfers and payments (33\% of the market);

- Provision of loans and credits (20\% of the market);

- Capital management ( $12 \%$ of the market);

- Currency operations (10\% of the market);

- Insurance operations ( $7 \%$ of the market);

- Other directions ( $18 \%$ of the market).

In the modern world the development of such systems is extremely important, as the mobility of payments appears and the software allows to automate the operational, accounting and management activities; increase the volume of information; manage sales channels; conduct business analysis, but not all financial technologies are focused on competing with banks, there are also those that supplement Internet banking, automate the banking system, simplify the process of communication with customers [4].

As for regulatory technologies, they appeared not long ago, at the end of 2007, and the global financial crisis that began in the United States was the impetus for their development. In this situation, regulators have shown their inability to control the banking sector, especially in mortgage lending.

Regulatory technologies are a subsystem of financial technologies that ensures more effective implementation of regulatory requirements for participants of financial markets. Regtech reduces the cost of services for participants in the financial market and the costs of state regulatory bodies by reducing time costs and making the whole system more simple (understandable to simple users) [5].

The rapid development of the RegTech segment is connected with the fact that all innovations in this area are directed to completing the existing system of financial turnover and does not need a radical reorientation of the organization. According to the American company IBM, at least 20,000 regulatory requirements are issued each 
year in the world, and by 2020 the total list of norms will have exceeded 300 million pages. Naturally, in the condition of globalization, when there are no borders between countries and international transfers are an integral part of the activities of many companies, it is extremely difficult to monitor compliance with all the standards. To do this, there are Regteh startups that make it easier to understand the system, automate the process of tracking changes [6].

The main functions of the RegTech are:

- Checking the data;

- Automation of the reporting process;

- Data security.

Among the companies engaged in data verification, Identitymind or KYC-chain can be identified, which have achieved successes in the initial audit of clients according to the program "Know Your Customer". Also there are companies involved in verifying the compliance of identity documents, or verifying bank accounts. As for the automation of reporting, their activities are mainly aimed at regulation of loans, taking into account ethnic groups and gender. The collected information is a basis for the automatic generation of financial statements. In February 2017, Verisk Analytics, a data analysis company, bought the start-up technology Fintellix that makes authorization of reporting.

One of the most important branches of Regtech's development is data security, as the number and speed of operations are not important if the facilities are not protected from cyberattacks. From the point of view of financial monitoring, this direction is a priority, as it actively involves the development of cybersecurity software and the company of the private sector of the economy.

According to the Forbes magazine in 2016, 158 billion dollars were lost in the world as a result of cybercrime. Taking into account modern technical capabilities the criminal funds can be transferred to offshore zones in a very short period, or withdrawn from circulation, by means of conducting a series of simple transactions in order to hide the origin of money.

According to cybersecurity, different areas of data protection can be singled out:

- Identification of customers: most gadgets allow to make multi-factor identification, fingerprints, retina, smile, and even behavioral features, which generally reduces time costs and risks; 
- Cyber insurance: reducing the risk of losses from cyber attacks using the principles of classical insurance (insurance premiums);

- Secure data transfer: use of data encryption, and special communication channels to reduce the risk of data leakage;

- Behavior analysis: multifactorial analysis of the behavior of employees to identify deviations;

- Testing cyberattacks: the method allows to simulate the situation and identify weaknesses in the organization's security system;

- Protection of communication and signal transmission: protection of cameras, computers, telephones in order to prevent surveillance and commercial espionage [1].

In Russian practice, bank institutions are actively involved in the development and application of regulatory technologies that already exist. For example, "Sberbank" has developed a mobile application that allows to identify customers using the "Face ID" technology. VTB Bank expects the full implementation of the Self-authentication system till the end of the year. Bank Avangard has implemented a display on the bank card with one-time passwords to confirm transactions. Bank "Tinkoff" is developing identification by voice, which allows to recognize the client in 15 seconds.

The markets of financial and regulatory technologies are developing rapidly, like most areas of the electronic information sphere, the entry to the market is simplified every year, the value barrier is reduced, therefore, it can be predicted that the entire financial market will be reoriented from the banking sector to the alternative in the nearest future. This is also proved by the fact that simple consumers need banking services but not banking institutions.

However, despite the increased mobility of payments the risks of reducing control in certain segments of the financial sphere are increasing from the point of view of financial monitoring. As it was mentioned above, the increasing cybersecurity is certainly a positive moment, but at the same time automation of the reporting process raises the need of the qualitative analysis of the getting data. The formation of reliable financial statements is based on the basic principle of accounting: "Reflection of operations by content and not by form", so it is impossible to eliminate the human factor at the present stage completely.

We believe that with the successful implementation of Regtech, the level of responsibility of lawyers, but not analysts, decreases. The activity of the analyst is connected with the following analytical procedures: 
- a study of unusual financial reporting items of quantities or unexpected relationships between them;

- an explanation of the most important changes in financial statements in comparison with similar items of the previous year or planned indicators;

- calculation and control of the dynamics of the main financial indexes of the organization and also analytical coefficients;

- conclusion about changes in the property and financial situations of the organization [2].

Having analyzed the changes in individual financial statements, it is necessary to predict their significance in the future, and also to consider the basic rates of growth.

So the purpose of an analyst's work in financial intelligence while studying the correctness of the formation of financial performance of the organization is:

- first, the establishment of compliance of accounting information on the accumulation of costs that are sold to regulatory documents, the correctness of accounting for activity costs and compliance with the adopted accounting policies; the legality of classification of expenses and their reflection in the accounting and financial reporting registers;

- secondly, the establishment of objective truth regarding the reliability, correctness and legality of reporting revenues and expenses.

In every organization, analytical work involves the movement of the entire complex of assets, liabilities and changes in the capital structure in order to prevent money laundering and terrorist financing [2].

While using the innovative software of Fintech and Regtech, it is possible to track quantitative and qualitative changes in the financial statements, but the activity constructed on using the data obtained cannot be $100 \%$ objective without an item-by-item qualitative analysis of the reporting.

In this regard, it is possible to propose to improve the efficiency of analyzing information in the AML / CFT system using innovative technologies, to introduce the process of assigning organizations to a certain level on the basis of a risk-oriented approach [3]: to divide organizations according to the type and branch of functioning into: simple, standard, complex:

- for organizations engaged in the sectors of the national economy with the lowest level of risk (simple), where only quantitative analysis is possible to obtain 
reliable data - use only the software tools, reducing the human factor to a minimum;

- organizations that are not highly exposed to be involved in the shadow economy because of the specifics of the industry or type of activity (standard), involve a specialist for carrying out analytical procedures based on the software data, and in case of discrepancies or non-standard indicators - making additional analysis;

- organizations in the high-risk group who have specific proportions in the formation of reporting (complex), whose activities can be reliably evaluated only in qualitative terms, involve analysts in order to prevent involvement in criminal schemes.

In order to achieve the success of the application of analytical procedures for financial results, we suggest dividing all audit objects into four classification groups:

1. elements of the enterprise accounting policy about income, expenses and financial results;

2. business transactions to record revenues, expenses and financial results;

3. accounts in primary documents, registers of accounting and reporting about incomes, expenditures, financial results;

4. information about incomes, expenses and financial results in the materials of previous inspections.

The application of this method with the active use of regulatory technologies makes it possible to increase the mobility of funds, reduce time costs, reduce the need to attract lawyers in specific industries, and the redistribution of analytical efforts by levels will improve the quality of the results obtained, as the main goals and tasks will be carried out in full volume, namely:

- improving the degree of understanding of the organization's activities, assessing the compliance of planning data with preliminary data;

- identification of areas of potential risk;

- an estimation of a risk level of the analyst;

- to reduce the number and volume of procedures, rational allocation of resources. 


\section{Conclusion}

Thus, we believe that, taking into account the rapid development of technology in all sectors of the national economy, the reductions of cyclicality of the market, the reduction of barriers' cost, the development of Finteh and Regtech will continue. These innovations are made to increase the mobility, efficiency and legitimacy of financial transactions. They will gradually lead to changes in the traditional banking system. This is facilitated by an annual increase in the number of regulatory standards, and the growing demand for these services (according to experts' information by 2020 the demand will increase to $\$ 118$ billion). As the current practice shows, the introduction of software that complements the existing system is in demand as it allows reducing costs without reducing the total level of control. However we find it impossible to exclude the human factor completely while conducting analytical procedures. As the financial results of the organization are affected by a huge number of both internal and external factors. Considering this, we made a proposal based on a risk-oriented approach to divide organizations into: results whose activities can be objectively evaluated exclusively by quantitative analysis; and those who need to attract specialists for the evaluation of the results. Such distribution of efforts will make it possible to simplify the entire system of settlements, crediting and currency exchange in a globalized economy, while maintaining the effectiveness of control over their legality.

\section{References}

[1] Alekhin A. What is RegTech: a new market for $\$ 120$ billion for financial startups / / A. Alekhin / May 17, 2017. - [Electronic resource]. - Access mode: https://rb.ru/opinion/regtech-what-is/

[2] Surnina K.S. Ensuring information security in the banking sector "Problems of Information Security" / Surnina K.S. // Proceedings of the III International scientific and practical conference: Crimean Federal University by V.I. Vernadsky." - Simferopol: - 2017.- P. 60-65.

[3] Surnina KS, Stepanko AD, Lishchishina OA AML / CFT system of the Republic of Crimea in the context of globalization (experience, problems, solutions) // K.C. Surnina, A.D. Stepanko, OA Lishchyshyna. - Collection of materials of the international scientific and practical conference of the network Institute in the field of AML / CFT "Threats and Risks for the World Economy". - Moscow, November 1-3, 2016 - p.186-192. 
[4] Finteh: models and classification // [Text]. - Articles. - [Electronic resource]. - Access mode: https://www.roomian.org/articles/fintech-kompanii-modeli-iklassifikatsiya-2017

[5] Shlogin D. Regteh: a fashionable word or a global trend? // D. Shlogin // Digitalization 2.0. - No. 2 (147) 2017 p. 16-17. - [Electronic resource]. - Access mode: https: //www.nsd.ru/common/img/uploaded/files/depo/147/16-17_Shlogin.pdf

[6] FinTech, RegTech and SupTech: What They Mean for Financial Supervision. Toronto Center, August 2017. - [Electronic resource]. - Access mode: http: //res. torontocentre. org/guidedocs/FinTech\%20RegTech\%20and\%20SupTech\% $20-\% 20$ What $\% 20$ They $\% 20$ Mean $\% 20$ for\%20Financial $\% 20$ Supervision. pdf 